\title{
The Effect of Electrochemical Oxygen Pumping on the Steady-State and Oscillatory Behavior of CO Oxidation on Polycrystalline Pt
}

\author{
I. V. Yentekakis and C. G. VAYenas ${ }^{1}$ \\ Institute of Chemical Engineering and High Temperature Chemical Processes, Department of Chemical \\ Engineering, University of Patras, Patras 26110, Greece
}

Received June 1, 1987; revised December 7, 1987

\begin{abstract}
The effect of electrochemically pumping $\mathrm{O}^{2-}$ to or from a porous polycrystallinc Pt catalyst film used for $\mathrm{CO}$ oxidation at atmospheric pressure and temperatures $250-600^{\circ} \mathrm{C}$ was studied. The $\mathrm{Pt}$ film served both as a catalyst and as an electrode of the solid electrolyte cell $\mathrm{CO}, \mathrm{O}_{2}, \mathrm{Pt} / \mathrm{ZrO} \mathrm{O}_{2}(8$ mole $\left.\% \mathrm{Y}_{2} \mathrm{O}_{3}\right) / \mathrm{Pt}, \mathrm{O}_{2}$. Under open-circuit conditions the Pt catalyst film operates as a regular $\mathrm{CO}$ oxidation catalyst. It was found that electrochemical $\mathrm{O}^{2-}$ pumping has a dramatic non-Faradaic effect on the steady-state and oscillatory behavior of $\mathrm{CO}$ oxidation on $\mathrm{Pt}$. The steady-state reaction rate typically increases or decreases by a factor of 2 but a $500 \%$ increase in reaction rate is observed under severely reducing conditions. The induced changes in reaction rate are typically two orders of magnitude higher than the rate of $\mathrm{O}^{2-}$ transfer to or from the catalyst and are always accompanied by the appearance of activation overpotential at the catalyst electrode. Reaction rate oscillations can be induced or stopped at will by adjusting the rate of $\mathrm{O}^{2-}$ transfer and consequently the potential of the catalyst-electrode. The frequency of electrochemically induced oscillations is linearly related to the applied $\mathrm{O}^{2-}$ current. The observed phenomena are completely reversible and are due to electrochemically induced changes in the oxidation state and catalytic properties of the platinum surface. These changes appear to result from changes in the work function of the metal due to the interaction of $O$ anions with the Pt surface. The very pronounced reaction rate increase upon $\mathrm{O}^{2-}$ removal under reducing conditions appears to be caused by $\mathrm{CO}$ decomposition followed by fast carbon combustion by gaseous $\mathrm{O}_{2}$. () 1988 Academic Press, Inc.
\end{abstract}

\section{INTRODUCTION}

The oxidation of $\mathrm{CO}$ on $\mathrm{Pt}$ is one of the most extensively studied catalytic reactions. Despite a very large number of experimental and theoretical studies there are still several unresolved questions regarding the exact reaction mechanism and the origin of the hysteresis, steady-state multiplicity, and limit cycle phenomena observed under both atmospheric and low-pressure conditions. Sheintuch and Schmitz (l) and Slin'ko and Slin'ko (2) have reviewed work prior to 1977. The surface science aspects of the $\mathrm{CO} / \mathrm{O}_{2} / \mathrm{Pt}$ system have been reviewed by Engel and Ertl (3) while mathematical modeling work prior to 1985 has been reviewed by Sheintuch (4). Both experimental and modeling work prior to 1985 have

1 To whom correspondence should be addressed. been thoroughly reviewed by Razon and Schmitz (5).

One of the most intriguing features of the Pt-catalyzed $\mathrm{CO}$ oxidation is its oscillatory behavior. Most of the recent work in this area seems to support the idea that the origin of oscillations is different at atmospheric pressure and under UHV conditions. Recent atmospheric pressure studies of $\mathrm{CO}(6-9)$ and ethylene (10-12) oxidation on Pt have provided strong experimental evidence that the oscillatory phenomena are caused by formation and decomposition of surface $\mathrm{PtO}_{2}$. Several surface spectroscopic techniques have been used to positively identify surface $\mathrm{PtO}_{2}(13,14)$ and to compare its dissociation pressure with that obtained under atmospheric pressure conditions $(12,14,15)$. At low pressures $\left(10^{-4}\right.$ Torr) the origin of oscillations appears to be different $(16-18)$. It was first shown by Ertl 
and co-workers that at low pressures sustained oscillations appear only on the $\operatorname{Pt}(100)$ surface and that during oscillations the surfacc undergocs periodic structural transformations between the $(1 \times 1)$ phase and a reconstructed hexagonal structure (16). Subsequent work by other groups has confirmed these low-pressure findings but has also provided strong evidence that at atmospheric pressure the oscillations are due to formation and decomposition of surface $\mathrm{PtO}_{2}(19,20)$.

The use of solid electrolyte cells as $\mathrm{O}^{2-}$ pumps to alter and to control the thermodynamic activity of adsorbed oxygen and consequently to influence the rate and selectivity of metal-catalyzed reactions has been demonstrated recently in a number of studies: Mason, Huggins, and co-workers found that the rate of $\mathrm{NO}$ decomposition on $\mathrm{Pt}$ and $\mathrm{Au}$ can be significantly increased by electrochemical $\mathrm{O}^{2-}$ pumping from the catalyst-electrode $(21,22)$. Stoukides and Vayenas found that both the rate and the selectivity of ethylene and propylene epoxidation on silver can be affected by $\mathrm{O}^{2-}$ pumping (23-25). Gür and Huggins showed that $\mathrm{O}^{2-}$ pumping from $\mathrm{Fe}, \mathrm{Co}$, and $\mathrm{Ni}$ catalyst-electrodes can increase significantly the rate of $\mathrm{CO}$ hydrogenation $(26,27)$. They attributed their results to an enhancement of the $\mathrm{C}-\mathrm{O}$ bond scission rate. Otsuka et al. found that the product selectivity of methane oxidation on $\mathrm{Ag}-\mathrm{Bi}_{2} \mathrm{O}_{3}$ catalysts can be markedly affected by $\mathrm{O}^{2-}$ pumping (28). Similar conclusions were reached by Seimanides and Stoukides who used $\mathrm{Ag}-$ $\mathrm{MgO}$ catalysts (29). More recently $\mathrm{Ha}-$ yakawa et al. found that propylene can be selectively oxidized to acrolein by $\mathrm{O}^{2-}$ pumping to an inert gold film (30). A common feature of some of these recent studies $(23-25,43)$ is that the change in reaction rate is non-Faradaic; i.e., it can be significantly higher than the rate of $\mathrm{O}^{2-}$ transport to or from the catalyst. This indicates that significant changes are occurring to the catalyst itself due to $\mathrm{O}^{2-}$ pumping. A quantitative description of these non-Faradaic electrocatalytic phenomena is not possible within the framework of classical Langmuir-Hinshelwood or Eley-Rideal models, unless one postulates the creation of new active centers $(23,24)$ or changes in the binding energies of chemisorbed species. Progress in the area of catalytic and electrocatalytic reactions in solid electrolyte cells has been recently reviewed (43).

Stabilized zirconia cells with appropriate catalytic electrodes have also been used for the simultaneous generation of electrical power and chemicals such as NO $(31,32)$, styrene $(33,34)$, and butadiene (35). In these systems it was also found that reaction rate and product selectivity are influenced by the $\mathrm{O}^{2-}$ current produced by the cell. However, in these cases the observed effects were Faradaic and could be reproduced by supplying the equivalent amount ( $i / 4 F)$ of oxygen from gas phase (43).

In the present paper we examine the effect of $\mathrm{O}^{2-}$ pumping on the rate of $\mathrm{CO}$ oxidation. Similar cells operating in a passive potentiometric mode have been used to monitor emf oscillations and to study the mechanism of $\mathrm{CO}$ oxidation on $\mathrm{Pt}(36-40)$.

\section{EXPERIMENTAL METHODS}

The experimental apparatus, including the zirconia flow reactor, is similar to the one used in previous papers $(10,11,23-25)$ and has been described in detail recently (40). Reactants and products of the zirconia continuous flow reactor which was operated at atmospheric pressure were analyzed by three independent techniques:

(a) On-line gas chromatography for $\mathrm{CO}$, $\mathrm{CO}_{2}, \mathrm{O}_{2}$, and $\mathrm{N}_{2}$ using a Perkin-Elmer sigma-3b gas chromatograph with a TC detector. A Porapak Q column was used to separate air and $\mathrm{CO}_{2}$ and a molecular sieve $5 \mathrm{~A}$ column was used to separate $\mathrm{N}_{2}, \mathrm{O}_{2}$, and $\mathrm{CO}$.

(b) On-line mass spectroscopy using a Balzers QMG 311 quadrupole mass spectrometer with a continuous gas sampling system and a QDP 101 data processor 
which allowed simultaneous recording of the $\mathrm{CO}_{2}$ and $\mathrm{O}_{2}$ transients during the experiments.

(c) On-line IR spectroscopy using a Beckman 864 nondispersive $\mathrm{CO}_{2}$ analyzer with a response time of $0.5 \mathrm{~s}$ which gave a higher sensitivity to the effluent $\mathrm{CO}_{2}$ signal than the mass spectrometer, due to the unavoidable vacuum system background noise at AMU 44.

Reactants were Linde standard $\mathrm{CO}$ diluted in $\mathrm{N}_{2}$ and Linde standard synthetic air. They could be further diluted with ultrapure $(99.999 \%) \mathrm{N}_{2}$. It was found necessary to preheat the reactants at $350^{\circ} \mathrm{C}$ in a spiral Pyrex tube placed before the reactor in order to completely decompose Fe carbonyl formed in the CO cylinder over long periods of time.

The zirconia flow reactor shown schematically in Fig. 1 has a volume of $30 \mathrm{~cm}^{3}$ and has been shown to be well mixed (CSTR) over the range of flow rates used in the present study by obtaining the reactor residence time distribution with a nondispersive IR $\mathrm{CO}_{2}$ analyzer (10). All results presented here were obtained with a total volumetric flow rate of $4.23 \mathrm{cc} \mathrm{STP/s}$.

The porous Pt catalyst film was deposited on the flat bottom of a stabilized zirconia tube ( 8 mole $\%$ yttria-stabilized zirconia) by applying a thin coat of Engelhard Hanovia A $1121 \mathrm{Pt}$ paste, followed by drying and calcining in air at $750^{\circ} \mathrm{C}$ for $2 \mathrm{~h}$ and subsequent treatment in a boiling $1 \mathrm{~N} \mathrm{HNO}_{3}$ solution for $1 \mathrm{~h}$ to remove surface impurities

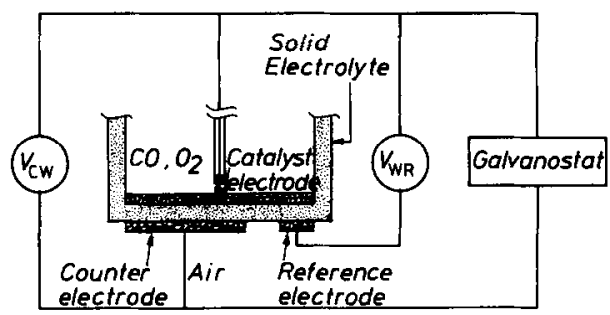

FIG. 1. Schematic diagram of the cell.

(38). The Pt film, approximately $5 \mu \mathrm{m}$ thick, was examined ex situ by XPS using an Al $K \alpha$ source $(1486.6 \mathrm{eV})$. The only detectable impurities were $\mathrm{C}$ and $\mathrm{O}$ both before and after reaction (46). The superficial surface area of the film was $2 \mathrm{~cm}^{2}$. The true surface area, too low to be measured accurately by $\mathrm{BET}$, was measured by a chemical titration technique using the $\mathrm{CO}_{2}$ IR analyzer as described elsewhere $(10,40)$. The reactive chemisorbed oxygen uptakes of the three different catalyst films used in the course of the experiments are given in Table 1 . The Pt catalyst film could also serve as the working electrode of the solid electrolyte cell shown in Fig. 1, i.e., $\mathrm{CO}, \mathrm{O}_{2}$, $\mathrm{CO}_{2}, \mathrm{Pt} / \mathrm{ZrO}_{2}\left(8\right.$ mole $\left.\% \mathrm{Y}_{2} \mathrm{O}_{3}\right) / \mathrm{Pt}$, air.

Two similar porous $\mathrm{Pt}$ films were deposited on the outside bottom wall of the stabilized zirconia tube as shown in Fig. 1. Both were exposed to ambient air. One of them, with a superficial surface area of $1.2 \mathrm{~cm}^{2}$, served as the counter electrode, and the other, with a superficial area of roughly 0.1 $\mathrm{cm}^{2}$, served as a reference electrode.

The flat bottoms of the zirconia solid

TABLE 1

\begin{tabular}{|c|c|c|c|c|c|}
\hline \multirow[t]{3}{*}{ Reactor } & \multirow{3}{*}{$\begin{array}{l}\text { Reactive oxygen } \\
\text { uptake of } \\
\text { catalyst-electrode } \\
\left(n_{\mathrm{O}} / \mathrm{g} \text { atom } \mathrm{O}\right)\end{array}$} & \multicolumn{4}{|c|}{ Relaxation times } \\
\hline & & \multicolumn{2}{|c|}{$i>0$} & \multicolumn{2}{|c|}{$i<0$} \\
\hline & & $\begin{array}{l}\text { Experimental } \\
\qquad(\tau / \mathrm{min})\end{array}$ & $\begin{array}{c}\text { Computed } \\
\left(\left(2 F n_{0} / i\right) / \mathrm{min}\right)\end{array}$ & $\begin{array}{l}\text { Experimental } \\
(\tau / \mathrm{min})\end{array}$ & $\begin{array}{c}\text { Computed } \\
\left(\left(2 F n_{\mathrm{O}} / i\right) / \mathrm{min}\right)\end{array}$ \\
\hline 1 & $3.64 \times 10^{-7}$ & $1.0(i=0.9 \mathrm{~mA})$ & 1.30 & $1.6(i=-0.6 \mathrm{~mA})$ & 1.96 \\
\hline 2 & $1.90 \times 10^{-7}$ & $2.5(i=0.4 \mathrm{~mA})$ & 1.53 & $2.4(i=-0.6 \mathrm{~mA})$ & 1.02 \\
\hline 3 & $1.34 \times 10^{-7}$ & $0.5(i=0.9 \mathrm{~mA})$ & 0.48 & $0.75(i=-0.6 \mathrm{~mA})$ & 0.72 \\
\hline
\end{tabular}


electrolyte tubes were diamond polished to thicknesses of the order of $400 \mu \mathrm{m}$ in order to reduce the resistance of the cell.

Constant currents or voltages were applied between the working and the counter electrodes by means of an AMEL 553 galvanostat-potentiostat. The catalyst temperature was controlled within $2^{\circ} \mathrm{C}$ and also measured with a second thermocouple attached to the wall of the stabilized zirconia tube at a distance of $1 \mathrm{~mm}$ from the counter electrode. The open end of the stabilized zirconia tube was clamped to an appropriately machined water-cooled stainless-steel cap. The cap had provisions for introduction of reactants and removal of products through Pyrex tubes and also for introduction of a Pt wire partly enclosed in a Pyrex tube to establish electrical contact with the catalyst electrode.

Under open-circuit conditions the film exposed to the reactants (working electrode) functions as a regular catalyst for $\mathrm{CO}$ oxidation. By measuring its potential relative to the reference or counter electrode one can determine the thermodynamic activity of oxygen on the catalyst during reaction $(10,40)$, which may differ substantially from the gas phase oxygen activity if oxygen adsorption is not in equilibrium during the reaction. When the circuit is closed and the galvanostat is used to apply a constant current $i$ between the working and the counter electrodes the oxygen ions $\mathrm{O}^{2-}$ are transferred to or from the working catalystelectrode at a rate $i / 2 F$, where $F$ is Faraday's constant. The potential difference $V_{\mathrm{WR}}$ between the working and the reference electrodes was continuously monitored during oxygen pumping. It equals theoretically the sum of the open-circuit cmf plus the overpotential of the working electrode (4I). In practice the reference electrode is never ideal and $V_{W R}$ always contains a nonzero ohmic component which we denote as IR. This component was determined using the current interruption technique and was subtracted from $V_{\mathrm{WR}}$ in order to obtain the IR-free catalyst potential.

\section{RESULTS}

Three different zirconia reactor cells were used in the course of the experiments. Close agreement was observed with all of them between measured and theoretical (Nernstian) open-circuit emf values when $\mathrm{O}_{2}$ and $\mathrm{N}_{2}$ mixtures of known $p_{\mathrm{O}_{2}}$ were fed through each cell reactor. This verified the pure anionic conductivity of the solid electrolyte. When $\mathrm{CO}-\mathrm{O}_{2}$ mixtures are fed through the reactor the open circuit emf $E$ takes values between -20 and $-900 \mathrm{mV}$. This indicates that the oxygen activity on the catalyst is much lower than the gas phase oxygen activity, because the intrinsic rate of $\mathrm{O}_{2}$ adsorption is comparable to the rate of the surface reaction $(10,40)$. The three zirconia reactor cells used in the experiments differed in the surface area of the platinum catalyst which also served as the working electrode (Table 1). Both galvanostatic and potentiostatic operations were explored in the course of the experiments and both modes of operation were found to produce similar results. All the results reported here were obtained galvanostatically, i.e., by imposing a constant current between the catalyst and the counter electrodes and monitoring the potential difference between the catalyst and the reference electrodes.

Figure $2 \mathrm{a}$ shows the effect of applying a constant current $i= \pm 400 \mu \mathrm{A}$ to cell reactor 1 while monitoring the reactor effluent $\mathrm{CO}_{2}$ concentration and thus the rate of the reaction under oxidizing gas phase conditions. At the start of the experiment the circuit is open and the catalyst is at a steadystate activity. At time $t=0$ the galvanostat is used to apply a current $i=400 \mu \mathrm{A}$ with a corresponding rate of oxygen transfer to the catalyst $G_{O}=i / 2 F=2.07 \times 10^{-9} \mathrm{~g}$ atoms $\mathrm{O} / \mathrm{s}$. This causes an increase in the rate of $\Delta r=1.68 \times 10^{-7} \mathrm{~g}$ moles $\mathrm{CO}_{2} / \mathrm{s}$ which is a factor of 81 greater than $G_{0}$. Defining an enhancement factor as $\Lambda=\Delta r / G_{0}$ one has in this case $\Lambda=81$. At the same time the voltage $V_{\text {WR }}$ between the catalyst and the 
reference electrode changes from $-128 \mathrm{mV}$ to a steady-state value of $+230 \mathrm{mV}$. Subsequently the circuit is opened and $r$ is restored to its initial value within $15 \mathrm{~min}$. The galvanostat polarity is then reversed and a current $i=-400 \mu \mathrm{A}$ is applied to the cell with a corresponding rate of oxygen removal from the catalyst $G_{0}=-2.07 \times 10^{-9}$ $\mathrm{g}$ atoms $/ \mathrm{s}$. This causes a decrease in the rate of $\Delta r=-0.51 \times 10^{-7} \mathrm{~g}$ moles $\mathrm{CO}_{2} / \mathrm{s}$ which corresponds to an enhancement factor $\Lambda=24.6$. At the same time the cell volt-
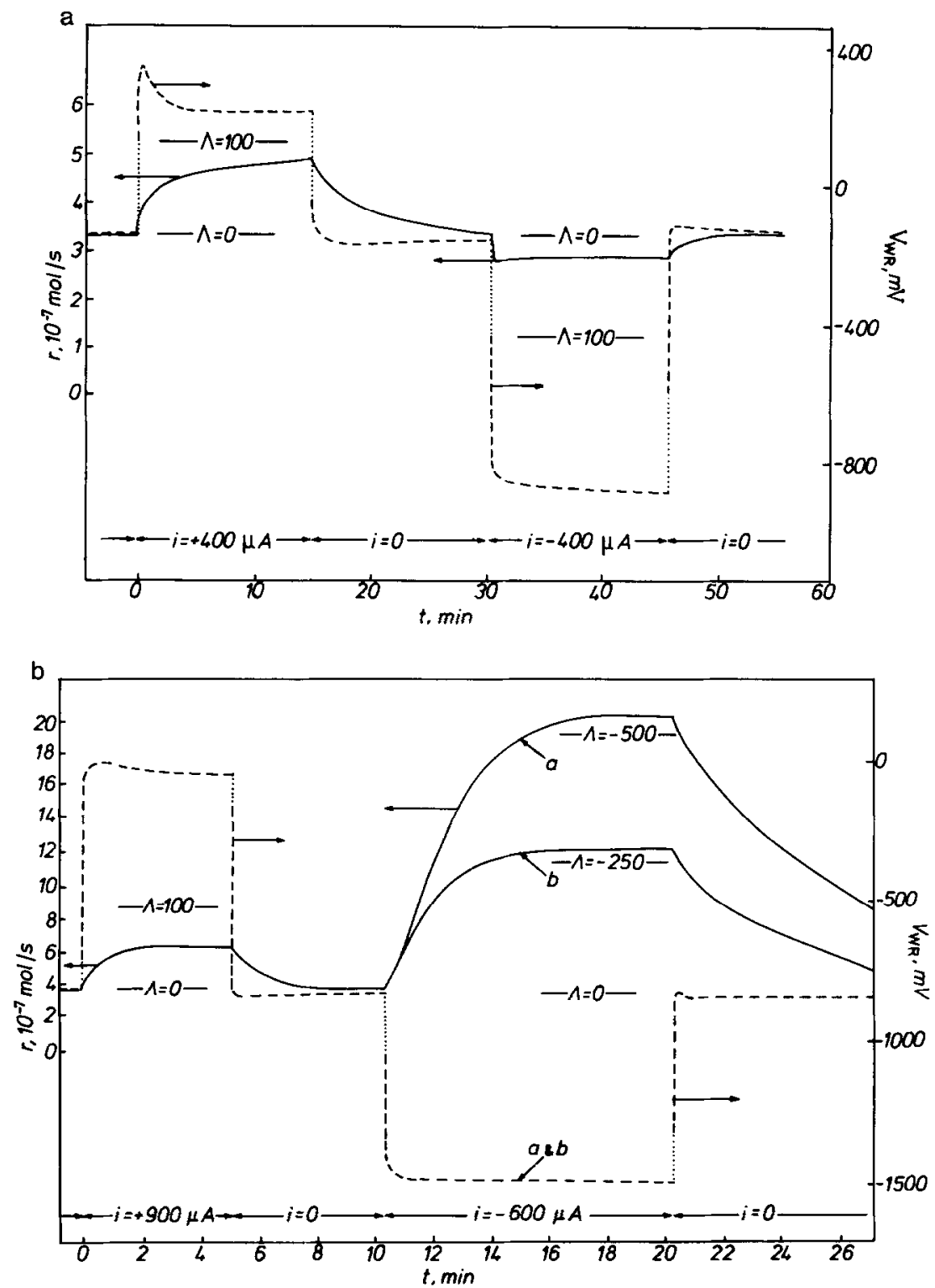

Fig. 2. Effect of electrochemical $\mathrm{O}^{2-}$ pumping on the rate of formation of $\mathrm{CO}_{2}$ (solid lines) and on catalyst potential relative to the reference electrode (broken lines). Inlet compositions and temperatures: (a) $p_{\mathrm{CO}}=4.7 \times 10^{-3}$ bar, $p_{\mathrm{O}_{2}}=0.1$ bar, $T=412^{\circ} \mathrm{C}$, reactor 1 ; (b) $p_{\mathrm{CO}}=2.9 \times 10^{-2}$ bar, $p_{\mathrm{O}_{2}}=4.03$ $\times 10^{-3}$ bar, $T=555^{\circ} \mathrm{C}$, reactor 1 ; (c) $p_{\mathrm{CO}}=2.8 \times 10^{-2}$ bar, $p_{\mathrm{O}_{2}}=3.84 \times 10^{-2} \mathrm{bar}, T=555^{\circ} \mathrm{C}$, reactor 2 . See text for discussion. 


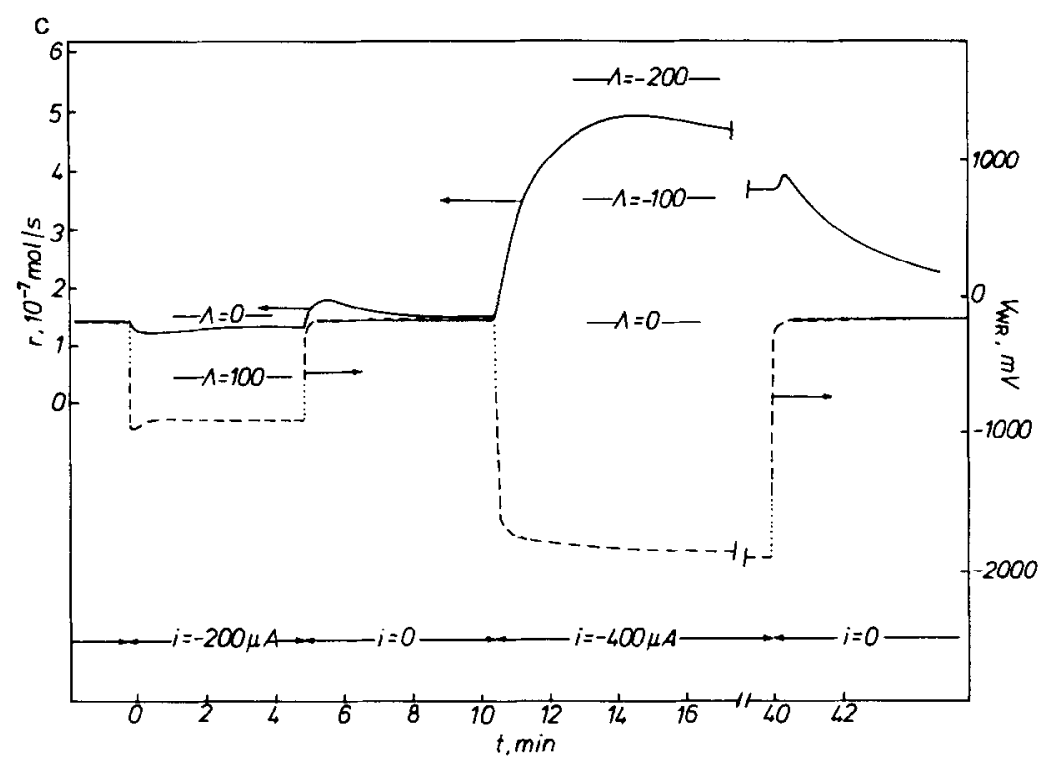

FIG. 2-Continued.

age gradually reaches a steady-state value $V_{\mathrm{WR}}=-840 \mathrm{mV}$. Finally the circuit is opened again and the catalyst activity and cell open-circuit emf relax to their initial values within a few minutes. Thus the phenomenon is reversible and no permanent change of the platinum catalyst has taken place.

As shown in Figs. $2 a, 2 b$, and $2 c$ the potential transients consist of two parts: a very rapid initial increase or decrease, shown by a dotted line and corresponding to an ohmic IR drop, and a subsequent gradual transient. It is the IR-free potential difference $V_{\mathrm{WR}}$-IR which gives the sum of the open-circuit emf $E$ plus the catalystelectrode overpotential $\eta_{c}$ for the threeelectrode system used here (4I). If the reference electrode were an ideal reference electrode then the IR term would practically vanish. During the course of the experiments it was found that IR-free voltages in excess of approximately $\pm 2.5 \mathrm{~V}$ should not be applied to the cell because this causes electrolysis of the solid electrolyte. Once zirconia has been reduced to metallic zirconium the cell resistance drops precipi- tously, the open-circuit emf drops to zero, no oxygen can be pumped to the catalyst, and the phenomenon disappears.

Figures $2 b$ and $2 c$ show the effect of applying constant currents but now under relatively reducing gas phase conditions. There are important similarities but also differences between these figures and Fig. 2a which was obtained under oxidizing gas phase conditions. The main similarity is that the rate increases when $\mathrm{O}^{2-}$ is pumped to the catalyst (positive currents) as shown in Fig. 2b. The corresponding enhancement factor is $\Lambda=48.7$. Similarly when small negative currents are applied the rate decreases as shown in Fig. $2 c(\Lambda=7.2)$. However, when the applied current is high enough so that the IR-free catalyst potential with respect to the reference electrode exceeds $-1.3 \mathrm{~V}$, then a dramatic increase in the rate is observed (Figs. $2 b$ and $2 c$ ). The curve labeled a on Fig. $2 b$ was obtained when a negative current of $-600 \mu \mathrm{A}$ was first applied to the cell after repetitive positive currents. This caused a nearly sixfold increase in the rate with a corresponding enhancement factor $\Lambda=-529$; i.e., removal 
of $\mathrm{O}^{2-}$ causes a very substantial increase in the rate. After several successive applications of $-600 \mu \mathrm{A}$ to the cell the increase in the rate stabilized to the one shown by curve $b$ in Fig. $2 b$ which gives an enhancement factor $\Lambda=-255$. As shown in the same figure the voltage behavior is practically the same for both cases a and $b$. The difference between curves $a$ and $b$ is an example of how the catalyst history can sometimes influence the magnitude of the observed effect.

The catalyst history also has an important effect on the shape of galvanostatic rate transients. This is shown in Fig. 3 which shows galvanostatic transients obtained with a positive current of $900 \mu \mathrm{A}$ under identical temperature and gaseous composition conditions. Curve a was obtained after large negative currents had been previously applied to the catalyst while curve $b$ was obtained after previous imposition of positive currents. The shapes of the rate transients are quite different but both give the same final steady-state increase.

The observed dramatic increase in reaction rate upon $\mathrm{O}^{2-}$ removal from the catalyst under reducing conditions leads to rates of $\mathrm{CO}$ oxidation more than a factor of 2 higher than the maximum rate obtainable on the same catalyst and at the same temperature for any gaseous composition under open-circuit conditions. It does not therefore appear feasible to explain this phenomenon by simple changes in the surface coverages of chemisorbed $\mathrm{CO}$ and atomic oxygen or even complete reduction of the Pt surface resulting from the continuous removal of $\mathrm{O}^{2-}$. The observation that this phenomenon occurs only when the IRfree voltage of the catalyst with respect to the reference electrode is more negative than $-1.3 \mathrm{~V}$ strongly suggests that complete or partial $\mathrm{CO}$ disproportionation is taking place on the catalyst surface; $\mathrm{CO}$ disproportionation is thermodynamically possible under these conditions. Carbon from $\mathrm{CO}$ disproportionation is then combusted by gaseous oxygen to produce $\mathrm{CO}_{2}$.

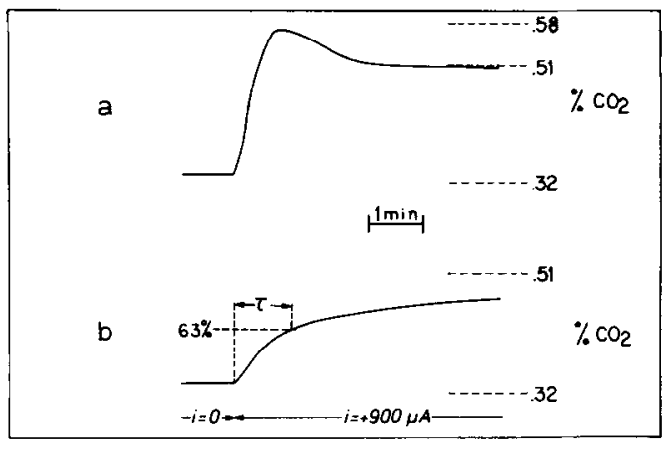

FIG. 3. Effect of catalyst history on the shape of the reaction rate transient upon application of a positive current of $900 \mu \mathrm{A}$. Curves $a$ and $b$ are obtaincd aftcr previous application of negative and positive currents, respectively. Inlet composition: $p_{\mathrm{CO}}=2.44 \times 10^{-2}$ bar, $p_{\mathrm{O}_{2}}=3.36 \times 10^{-2} \mathrm{bar}, T-555^{\circ} \mathrm{C}$, reactor 1 .

In many respects the phenomenon is similar to that observed upon application of voltages exceeding $-1.5 \mathrm{~V}$ during $\mathrm{CO}$ hydrogenation on transition metals $(26,27)$.

\section{Effect of Current Density}

Figure 4 shows the steady-state effect of applied current $i$ on the reaction rate and on the IR-free catalyst-electrode potential in an oxidizing gaseous composition. The same data are plotted in Fig. 5 as the relative increase or decrease in the rate $\left(\Delta r / r_{\mathrm{O}}\right)$ vs the ratio of the rate of $\mathrm{O}^{2-}$ transport to the catalyst $(i / 2 F)$ divided by the open-circuit $\mathrm{CO}$ oxidation rate $r_{\mathrm{O}}$. This mode of presentation has also been adopted in subsequent figures because it has the advantage that the enhancement factor of any data point can be immediately computed from the slope of the line connecting that particular point with the origin of the axes. As shown in Figs. 4-6 positive currents, i.e., $\mathrm{O}^{2-}$ pumping to the catalyst, generally increase the rate of $\mathrm{CO}$ oxidation but some exceptions have been observed and one is shown in Fig. 6. For increasingly positive currents a saturation and subsequent gradual decrease is usually observed in the rate increase $\Delta r$. This is similar to the behavior of $r$ vs $P_{\mathrm{O}_{2}}$ observed under open-circuit conditions (40) and may correspond to a saturation in the coverage of oxygen adsorbed on 

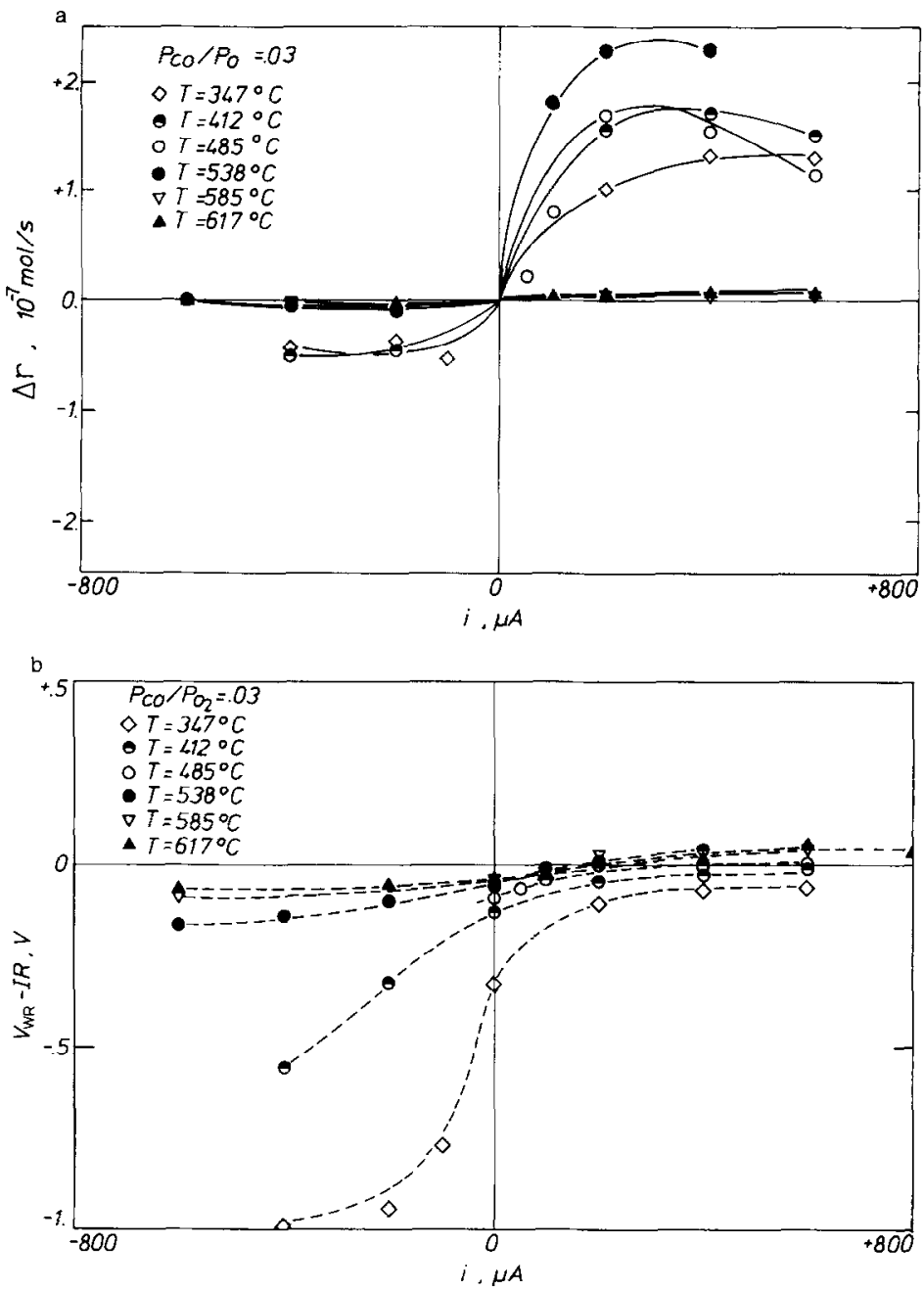

FIG. 4. Effect of current on the steady-state change in reaction rate $\Delta r$ (a) and on catalyst potential (b). Inlet composition: $p_{\mathrm{CO}}=4.7 \times 10^{-3}$ bar, $p_{\mathrm{O}_{2}}=0.16$ bar, reactor 1 .

the catalyst surface. $\Lambda$ s shown in Figs. 4-6 there exists a distinct maximum in $\Delta r$ with increasing $T$ at constant current. This maximum is observed at temperatures near $550^{\circ} \mathrm{C}$.

Negative currents, i.e., $\mathrm{O}^{2-}$ removal from the catalyst, under oxidizing gaseous conditions always cause a relatively small decrease in the rate (Figs. 4 and 5). It should be noted that the IR-free cell voltage does not reach $-1.3 \mathrm{~V}$ because the exchange current density is high since there is ample adsorbed oxygen which can be reduced to $\mathrm{O}^{2-}$.

Figure 6 shows the steady-state effect of applicd current in a morc reducing gaseous environment. For positive currents the effect is similar to that obtained in oxidizing environments; i.e., the rate usually increases until saturation or a shallow maximum is obscrved. The effect of negative currents however is more complex as shown in Fig. 6 and as previously discussed. Small negative currents, i.e., removal of $\mathrm{O}^{2-}$, cause a decrease in the rate, but high negative currents cause a dramatic increase in the rate as the IR-free voltage exceeds $-1.3 \mathrm{~V}$ and $\mathrm{CO}$ disproportionation and subsequent combustion can take place. This is also shown in Fig. 7 where the 

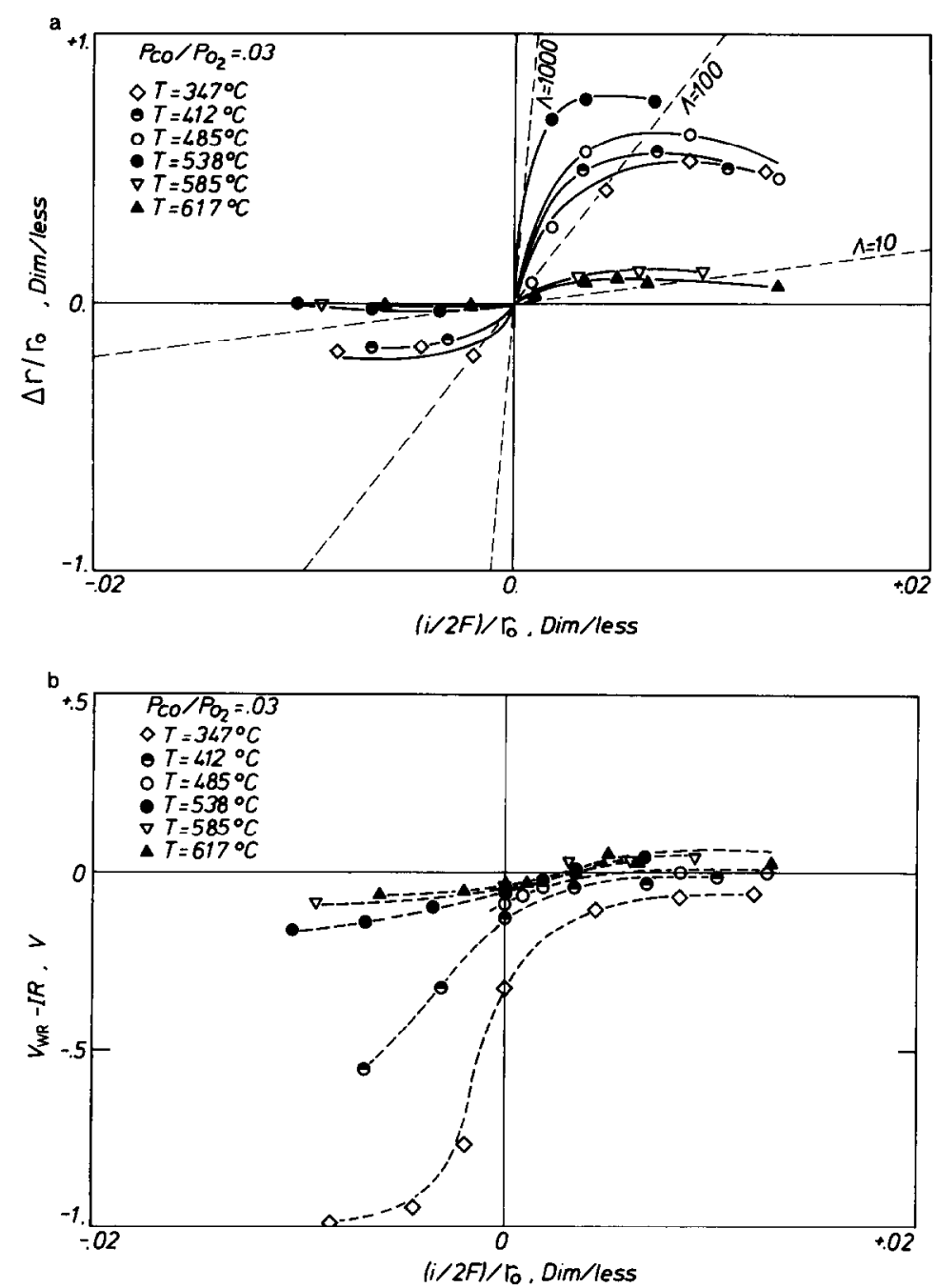

FIG. 5. Effect of dimensionless current on the dimensionless steady-state change in reaction rate (a) and on catalyst potential (b) under oxidizing conditions. Broken lines are constant enhancement factor lines. Conditions as in Fig. 4.

effect of current is studied at constant temperature and three different gaseous compositions. It can be seen that a rate enhancement with negative currents is observed only when the gaseous composition is reducing enough so that the IR-free voltage exceeds $-1.3 \mathrm{~V}$.

\section{Effect of Gaseous Composition}

Figure 8 shows typical results of the effect of gaseous composition on the steadystate open-circuit emf $E$ and on the rate $r$ when constant currents of 0.9 and $-0.6 \mathrm{~mA}$ are applied to the cell. These currents correspond to $G_{0}=4.66 \times 10^{-9} \mathrm{~g}$ atom $/ \mathrm{s}$ and $G_{0}=-3.11 \times 10^{-9} \mathrm{~g}$ atom $/ \mathrm{s}$, respectively. Application of a positive current is shown to increase the rate of the reaction at all gaseous compositions. The rate maximum is slightly shifted to higher $p_{\mathrm{CO}} / p_{\mathrm{O}_{2}}$ ratios. Negative current, i.e., oxygen removal from the catalyst, causes a slight decrease in the rate for $p_{\mathrm{CO}} / p_{\mathrm{O}_{2}}$ ratios roughly below unity and a dramatic increase in the rate under severely reducing conditions. 

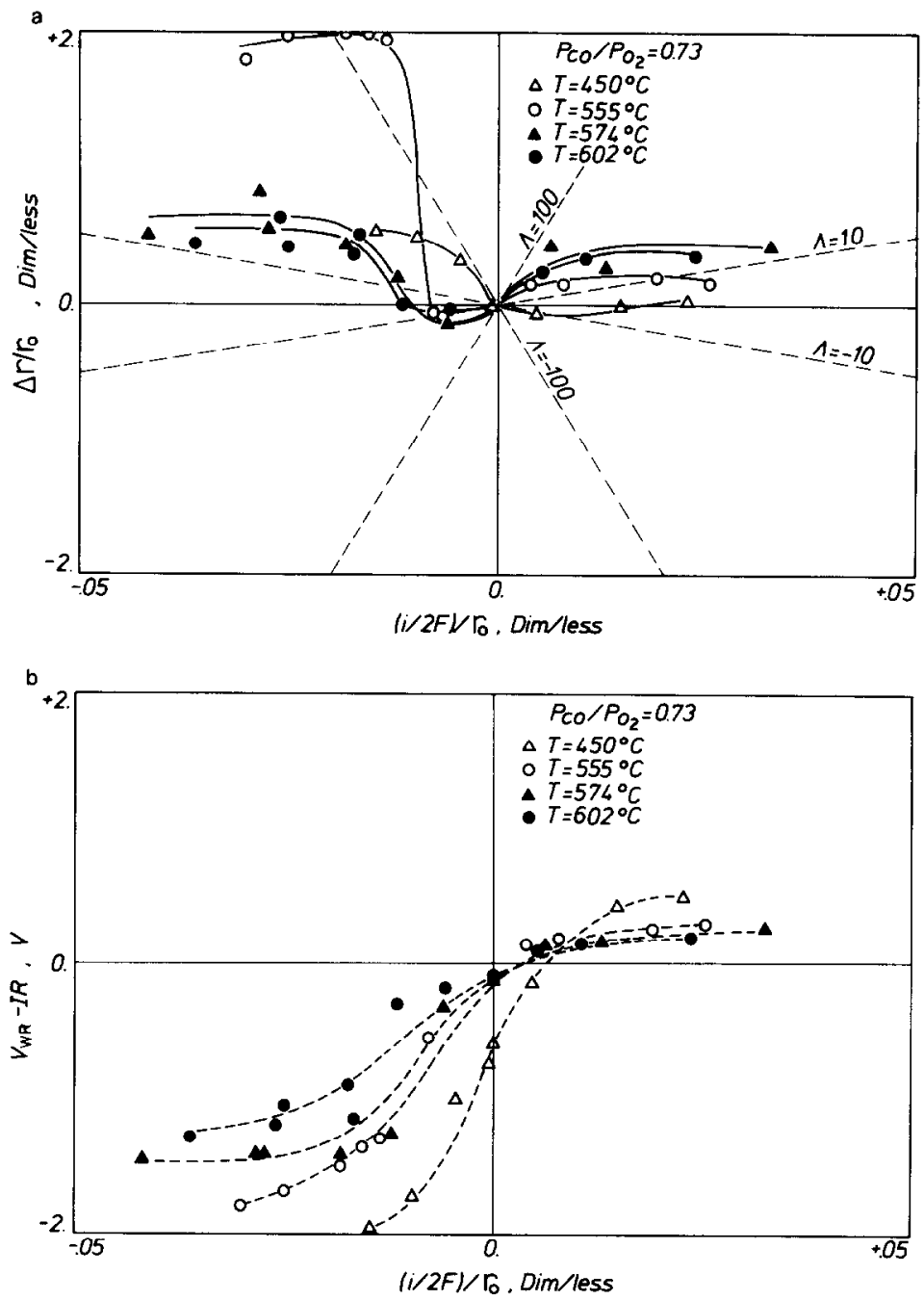

FIG. 6. Effect of dimensionless current on the dimensionless steady-state change in reaction rate (a) and on catalyst potential (b) under relatively reducing conditions. Inlet composition: $p_{\mathrm{CO}}=2.8 \times 10^{-2}$ bar, $p_{\mathrm{O}_{2}}=3.84 \times 10^{-2}$ bar. $(\mathrm{O}) r_{\mathrm{O}}=0.193 \mu \mathrm{mole} / \mathrm{s} ;(\triangle) r_{\mathrm{O}}=0.214 \mu \mathrm{mole} / \mathrm{s} ;(\Delta) r_{\mathrm{O}}=0.164 \mu \mathrm{mole} / \mathrm{s} ;(\bullet)$ $r_{\mathrm{O}}=0.186 \mu \mathrm{mole} / \mathrm{s}$; reactor 2 .

\section{Effect of Temperature}

The qualitative aspects of the effect of temperature on the rate increase or decrease $\Delta r$ for constant gaseous composition and constant positive or negative applied current are shown in Fig. 9. For positive currents there is a distinct maximum in the rate enhancement $\Delta r$. Negative currents, i.e., $\mathrm{O}^{2-}$ removal from the catalyst, have an increasingly negative effect on $\Delta r$ until a temperature is reached where $\Delta r$ becomes positive and increases with an apparent activation energy of roughly $30 \mathrm{kcal} / \mathrm{mole}$.

\section{Effect of Current on the Oscillatory Behavior of $\mathrm{CO}$ Oxidation}

As shown in Figs. 10 and 11 the rate and emf oscillations of $\mathrm{CO}$ oxidation can be started or stopped at will by imposition of appropriate currents. Thus in Fig. 10 the 


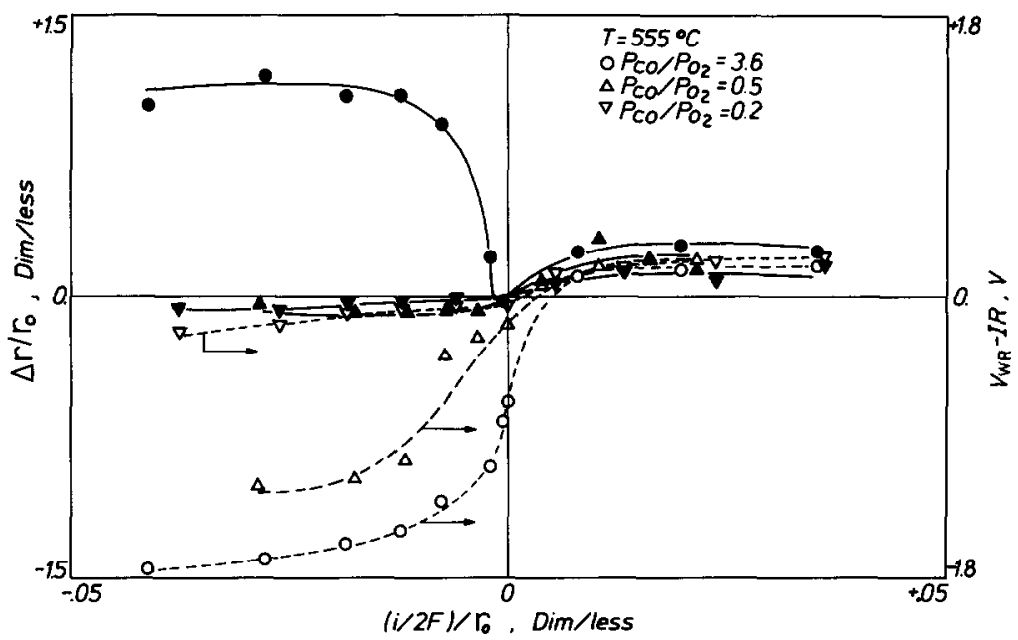

FIG. 7. Effect of dimensionless current on the dimensionless steady-state change in reaction rate (filled symbols) and on catalyst potential (open symbols) at varying inlet gaseous composition. ( $\mathrm{O}$ and -) $p_{\mathrm{CO}}=3.14 \times 10^{-2} \mathrm{bar}, p_{\mathrm{O}}=8.86 \times 10^{-2} \mathrm{bar}, r_{0}=0.153 \mu \mathrm{mole} / \mathrm{s}$. $(\triangle$ and $\Delta) p_{\mathrm{CO}}=2.59 \times 10^{-2} \mathrm{bar}$, $p_{\mathrm{O}_{2}}=5.18 \times 10^{-2}$ bar, $r_{\mathrm{O}}=0.272 \mu \mathrm{mole} / \mathrm{s}$. $(\nabla$ and $\nabla) p_{\mathrm{CO}}=1.92 \times 10^{-2}$ bar, $p_{\mathrm{O}_{2}}=9.81 \times 10^{-2}$ bar, $r_{\mathrm{O}}=$ $0.182 \mu \mathrm{mole} / \mathrm{s}$; reactor 3 .

catalyst is originally at a stable steady state. Imposition of a negative current merely decreases the rate but imposition of a positive

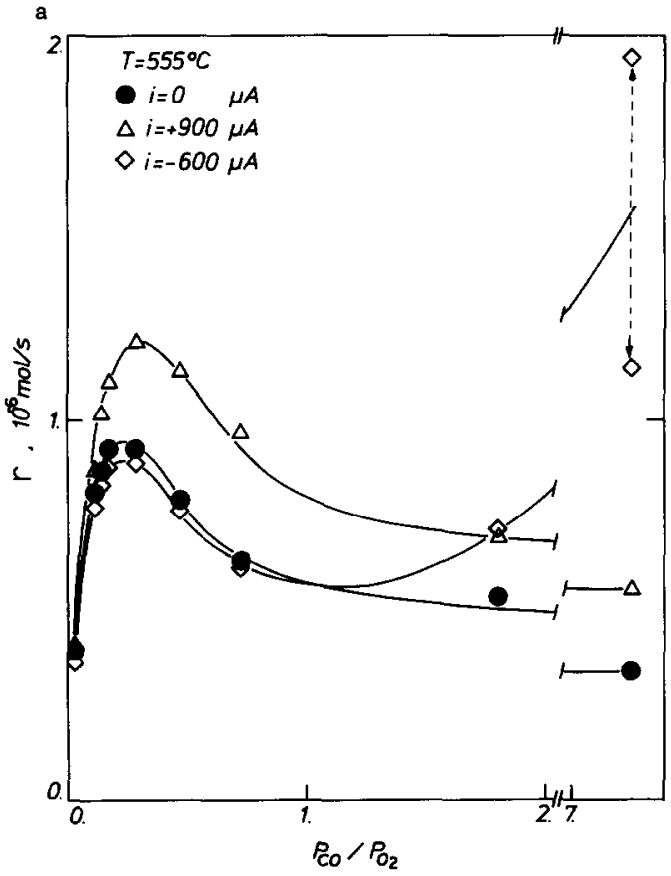

current of $200 \mu \mathrm{A}$ leads to an oscillatory state with a period of $80 \mathrm{~s}$. The effect is completely reversible and the catalyst re-

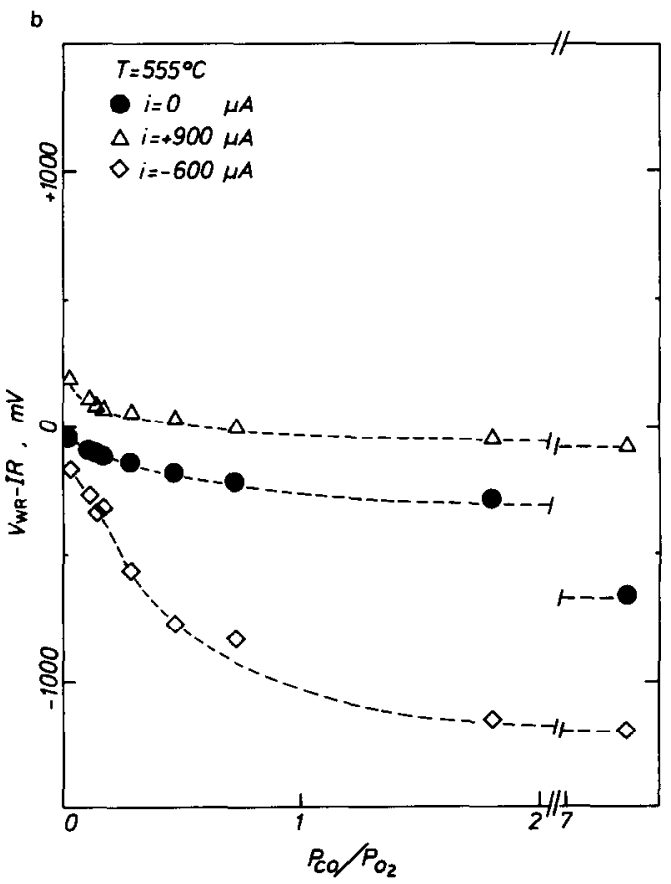

FIG. 8. Effect of inlet gaseous composition on the steady-state reaction rate (a) and catalyst potential (b); reactor 1 . 


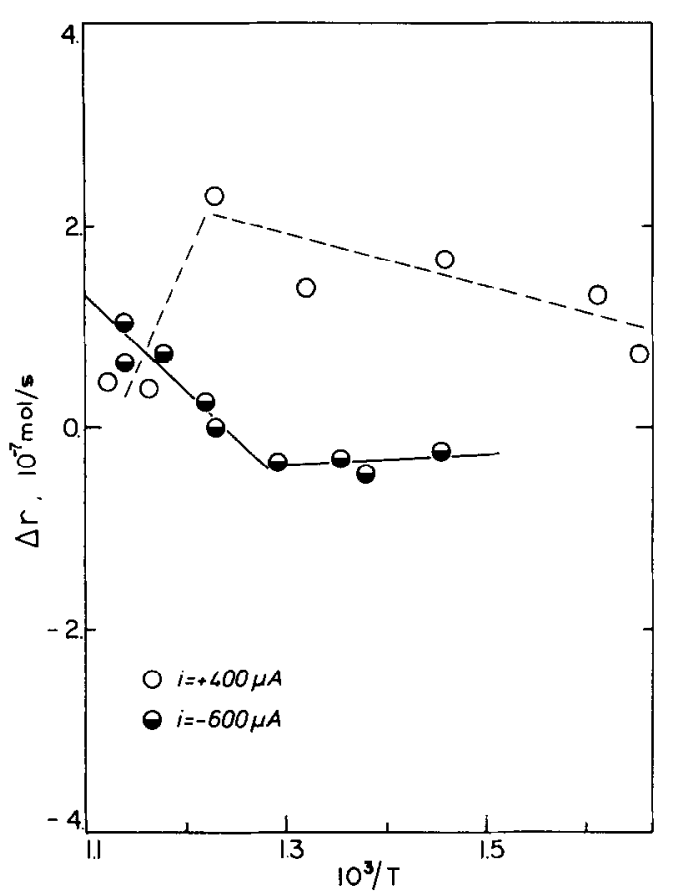

Fig. 9. Temperature dependence of the steady-state reaction rate change $\Delta r$ at constant positive and negative applied current. Inlet compositions: $(0) p_{\mathrm{CO}}=4.7$ $\times 10^{-3}$ bar, $p_{\mathrm{O}_{2}}=0.16$ bar, reactor $1 ;(\Theta) p_{\mathrm{CO}}=2.8 \times$ $10^{-2}$ bar, $p_{0_{2}}=3.84 \times 10^{-2}$ bar, reactor 2 . turns to its initial steady state upon current interruption. The opposite effect is depicted in Fig. 11 where the catalyst under open-circuit conditions exhibits stable limit cycle behavior with a period of $184 \mathrm{~s}$. Imposition of a negative current of $-400 \mu \mathrm{A}$ leads to a steady state. Upon current interruption the catalyst returns to its initial oscillatory state. Application of positive currents leads to oscillatory states characterized by higher frequencies.

A striking feature of the effect of current on the oscillatory behavior of $\mathrm{CO}$ oxidation on $\mathrm{Pt}$ is shown in Fig. 12. It can be seen that the frequency of oscillations is a linear function of the applied current. As shown in the figure this observation holds not only for intrinsically oscillatory states, i.e., those which have a nonzero frequency at $i=0$, but also for those which do not exhibit oscillations under open-circuit conditions, such as the ones shown in Fig. 10.

\section{DISCUSSION}

The observed phenomena clearly show that the nature of the platinum catalyst is changing significantly during electrochemi-

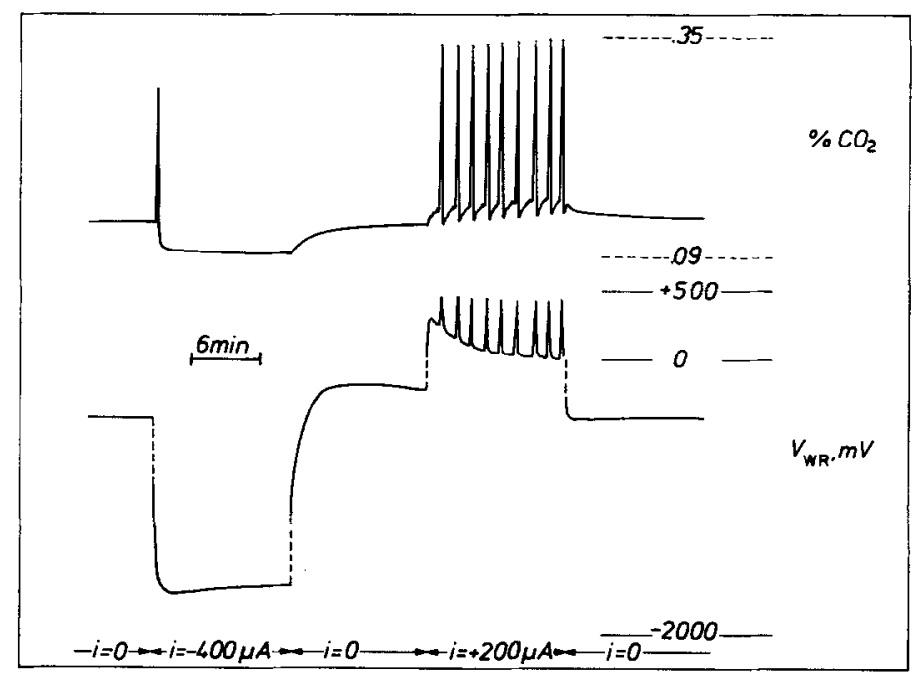

FIG. 10. Induction of rate and catalyst potential oscillations by $\mathrm{O}^{2-}$ pumping. Top and bottom curves show $i$ i.e behavior of the mole fraction of effluent $\mathrm{CO}_{2}$ and $V_{W R}$, respectively. Inlet composition: $p_{\mathrm{CO}}=$ $4.7 \times 10^{-3}$ bar, $p_{\mathrm{O}_{2}}=0.16 \mathrm{bar}, T=297^{\circ} \mathrm{C}$, reactor 1 . 


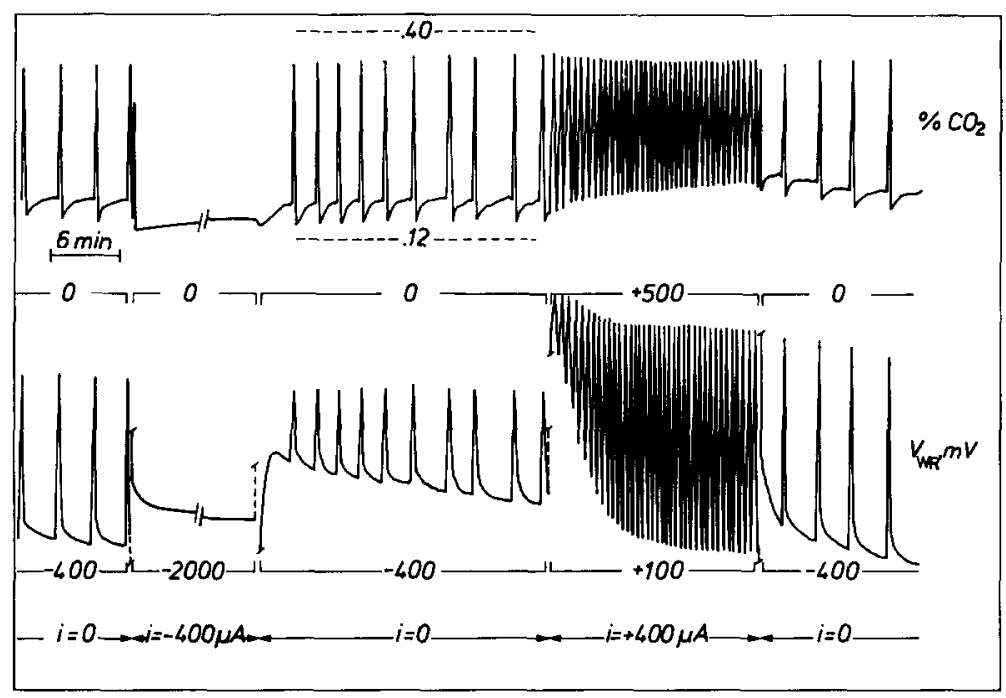

FIG. 11. Transition from an oscillatory state to a steady state and to a higher-frequency oscillatory state upon application of negative and positive current, respectively. Top and bottom curves show the behavior of the mole fraction of effluent $\mathrm{CO}_{2}$ and $V_{\mathrm{WR}}$, respectively. Inlet composition: $p_{\mathrm{CO}}=4.7 \times$ $10^{-3}$ bar, $p_{\mathrm{O}_{2}}=0.16$ bar, $T=332^{\circ} \mathrm{C}$; reactor 1 .

cal oxygen pumping. The increase or decrease in the rate of $\mathrm{CO}$ oxidation is more than two orders of magnitude greater than the rate of oxygen pumping through the electrolyte. It can be easily shown that the electrolyte temperature cannot rise locally more than $2 \mathrm{~K}$ at most, due to $\mathrm{I}^{2} \mathrm{R}$ heat generated during $\mathrm{O}^{2-}$ pumping. The electrolyte temperature was measured at a distance of $1 \mathrm{~mm}$ from the counter electrode and no measurable temperature rise was observed during pumping. The absence of local catalyst heating due to oxygen pumping is also demonstrated by the fact that upon reversing the direction of pumping the change in the rate $\Delta r$ usually changes sign.

Internal gas phase diffusional limitations inside the porous $\mathrm{Pt}$ film are totally absent under the conditions of these experiments $(10,40)$. External concentration gradients have also been shown to be negligible ( 10 , 40). Thus it can be safely concluded that it is the intrinsic properties of the platinum catalyst which change during electrochemical oxygen pumping.

When oxygen is pumped to or from the catalyst the thermodynamic activity or oxygen on the platinum catalyst increases or decreases significantly because of the externally applied voltage. It thus becomes possible not only to affect the surface coverage of chemisorbed oxygen but also to at least partly oxidize or reduce the platinum catalyst. The experimentally observed relaxation time constants are of order 0.5-10 min and show conclusively that the observed phenomena involve surface rather than bulk oxidation of the platinum crystallites. The reactive oxygen uptake $n_{0}$ of the polycrystalline $\mathrm{Pt}$ films used was typically $2 \times 10^{-7} \mathrm{~g}$ atoms O. Typical currents employed in the present study were of order $600 \mu \mathrm{A}$ corresponding to a transport of $1.56 \times 10^{-9}$ moles $\mathrm{O}_{2} / \mathrm{s}$ through the electrolyte. Thus the time required to fully cover the Pt surface with atomically chemisorbed oxygen or to form a monolayer of $\mathrm{PtO}_{2}$ is of order 1 and $2 \mathrm{~min}$, respectively, in very good agreement with the experimental relaxation times. This is shown in Table 1 where experimental $(\tau)$ and computed $\left(2 F n_{\mathrm{O}} / i\right)$ relaxation times are compared for 


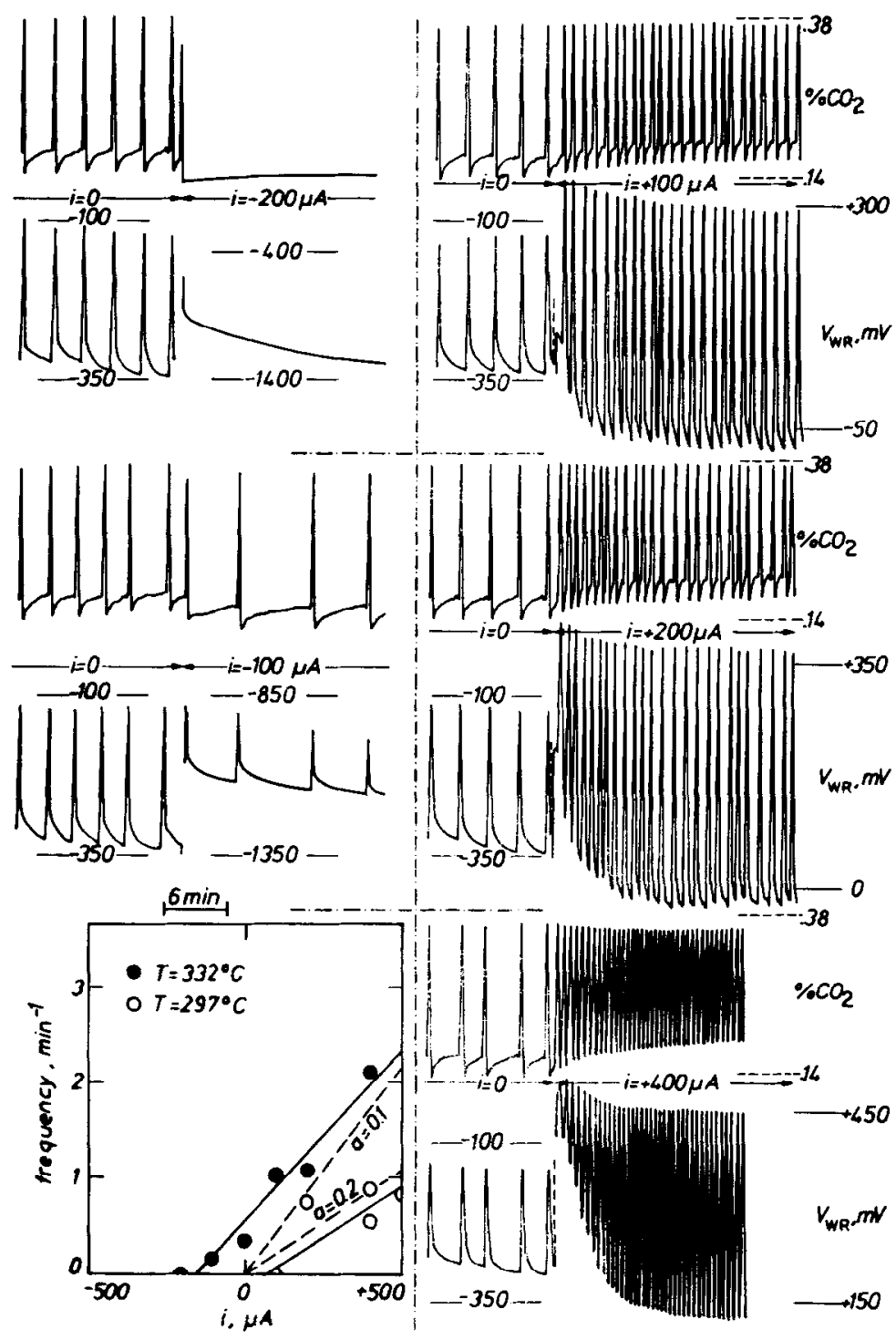

FIg. 12. Effect of applied current on the frequency of rate and emf oscillations. Conditions as in Fig. 11. Filled circles on the frequency vs current diagram represent oscillatory states of this figure; open circles include states shown in Fig. 10; reactor 1.

the three catalysts used. The experimental relaxation time $\tau$ was defined as the time required for the rate increase or decrease to reach $63 \%$ of its final steady-state value as shown in Fig. 3. This definition is appropriate for the galvanostatic response of firstorder systems, i.e., $\Delta r \sim(1-\exp (-t / \tau))$, which closely approximates most of the experimentally observed transients for both positive and negative currents. The only notable exception is in the case where a positive current follows previous application of a negative current (Fig. 3) in which case $\tau$ would deviate from the values shown in Table 1 because of the complexity of the galvanostatic transient. The notably good agreement shown in Table 1 between $\tau$ and $2 F n_{\mathrm{O}} / i$ shows conclusively the following. 
(a) The observed changes in reaction rate involve changes in the surface and not in the bulk of the Pt catalyst crystallites, in which case the relaxation time constants would be at least four orders of magnitude longer.

(b) The entire surface of the porous $\mathrm{Pt}$ catalyst film undergoes changes in its oxidation state and in the coverages of adsorbed $\mathrm{O}$ and $\mathrm{CO}$, although the reaction

$$
\mathrm{O}(\mathrm{ad})+2 \mathrm{e}^{-} \rightleftharpoons \mathrm{O}^{2-}
$$

takes place only at the three phase boundaries between the platinum catalyst, the gas phase, and the solid electrolyte. This behavior is similar to that observed during $\mathrm{O}^{2-}$ pumping to silver epoxidation catalysts (23-25) and suggests a significant mobility of chemisorbed species on the catalyst surface.

The main experimental observations can be grouped as follows.

(I) The reaction rate increases dramatically with large negative currents in reducing environments and high temperatures. When this happens the IR free voltage levels to values exceeding $-1.3 \mathrm{~V}$ (Figs. 2b, 2c, 6, 7, 8).

(II) The reaction rate usually increases with positive currents and always decreases with negative currents in an oxidizing environment (Figs. 2a, 3, 4, 5, 7, 8).

(III) Rate oscillations can be started or stopped at will by application of appropriate currents (Figs. 10 and 11).

Observation (I), as already discussed, very strongly suggests that large negative currents in reducing environments cause $\mathrm{CO}$ disproportionation followed by fast combustion of carbon by gaseous $\mathrm{O}_{2}$. This mechanism of $\mathrm{CO}_{2}$ formation, which is not available under open-circuit conditions to Pt catalysts, becomes thermodynamically possible since the IR-free voltage of the catalyst with respect to the reference electrode is more negative than $-1.3 \mathrm{~V}$ and leads to rates of $\mathrm{CO}_{2}$ formation more than a factor of 2 higher than open-circuit rates obtained at the same temperature for any gaseous composition (Fig. 8). The proposed interpretation of the observed phenomenon is further corroborated by the following three experimental observations.

(a) The phenomenon takes place only under reducing gas phase conditions, i.e., when the catalyst surface is almost entirely covered by chemisorbed CO. Under these conditions the only possible cathodic reaction is

$$
\mathrm{CO}(\mathrm{ad})+2 \mathrm{e}^{-} \rightarrow \mathrm{C}(\mathrm{ad})+\mathrm{O}^{2-}
$$

The usual cathodic reaction

$$
\mathrm{O}(\mathrm{ad})+2 \mathrm{e}^{-} \rightarrow \mathrm{O}^{2-}
$$

must take place only to a very small extent, since the coverage of chemisorbed oxygen is very small.

(b) The rate enhancement decreases rapidly with decreasing temperature at constant current, as shown in Fig. 9. The apparent activation energy is of order 30 $\mathrm{kcal} / \mathrm{mole}$. This implies that at low temperatures $\left(T<450^{\circ} \mathrm{C}\right)$ gaseous oxygen cannot oxidize rapidly the carbon formed on the surface. The observed activation energy is close to the value of $27 \mathrm{kcal} / \mathrm{mol}$ reported for carbon oxidation (42).

(c) When the negative current is discontinued, the rate of $\mathrm{CO}_{2}$ formation goes through a maximum as a function of time before it relaxes to its open-circuit value (Fig. 2c). This maximum is more pronounced when a positive current follows application of a negative current (Fig. 3). These transient rate maxima are observed only after application of negative currents in reducing environments and must be caused by the oxidation of carbon stored on the surface due to reaction (2).

Observation (II) can be interpreted, but only in a qualitative manner, by changes occurring in surface coverages of adsorbed species as a result of oxygen pumping. Oxygen pumping to the catalyst increases the thermodynamic activity and coverage of 
adsorbed oxygen; thus the rate can increase. If however the sum of the opencircuit coverages of adsorbed $\mathrm{O}$ and $\mathrm{CO}$ is near unity, then an increase in $\theta_{O}$ would cause a decrease in $\theta_{\mathrm{CO}}$ and thus a possible decrease in the product $\theta_{\mathrm{O}} \theta_{\mathrm{CO}}$ which is proportional to the reaction rate. Such rate decreases with positive currents have been observed at low temperatures (e.g., Fig. 6) where the sum of open-circuit coverages $\theta_{0}+\theta_{\text {co }}$ must be near unity. However, such a decrease in reaction rate with positive currents can also be caused by $\mathrm{PtO}_{2}$ formation $(6-15)$ which is also possible at temperatures roughly below $550^{\circ} \mathrm{C}(12,15)$. The existing experimental information does not permit an unambiguous discrimination between the two interpretations. It is very likely that both mechanisms act in parallel.

However, it should be pointed out that the magnitude of the observed effect, i.e., $\Lambda \gg 1$, cannot be explained quantitatively by any type of Langmuir-Hinshelwood or Eley-Rideal kinetic model if the rate constants of adsorption and surface reaction are not changing during $\mathrm{O}^{2-}$ pumping. Such changes will occur if the work function of the metal changes. However, the work function of the metal is indeed changing during $\mathrm{O}^{2-}$ pumping, under conditions where the catalyst electrode exhibits significant overpotential, due to the interaction of the Pt surface with excess oxygen anions, i.e., $\mathrm{O}^{2-}$ and also possible $\mathrm{O}^{-}$which is known to be an intermediate of reaction ( 1 ). A more detailed semiquantitative treatment of the effect of $\mathrm{O}^{2-}$ pumping on the rate of catalytic reactions on metals which accounts for such changes in the work function of the metal will be presented in two forthcoming papers $(44,45)$.

Figures 5 and 9 show that the rate increase $\Delta r$ exhibits a distinct maximum with temperature at any constant positive applied current. This observation can be explained as follows. At high temperatures the kinetics of the exchange reaction (1) are very fast; therefore no overpotential appears at the catalyst electrode and conse- quently there is no positive or negative excess of oxygen anions to interact with the Pt surface and induce changes in the work function of the metal. Under these conditions $\mathrm{O}^{2-}$ pumping affects only surface coverages but not reaction rate constants and its effect becomes Faradaic $(\Lambda=1)$ and therefore negligible. This also explains why only Faradaic effects have been observed upon oxygen pumping during ammonia, ethylbenzene, and butene oxidation on $\mathrm{Pt}$ catalyst electrodes $(31-35)$. In all these cases temperatures in excess of $600^{\circ} \mathrm{C}$ had been employed and no significant overpotential at the catalyst-electrode had been observed. The effect of temperature on $\Delta r$ shown in Fig. 9 is quantitatively similar to that observed with oxygen pumping on silver electrodes during ethylene epoxidation (24).

As shown in Figs. 4-7 small negative currents cause a decrease in reaction rate, provided the IR-free catalyst potential does not drop below $-1.3 \mathrm{~V}$. This can be qualitatively attributed to a decrease in the activity of adsorbed oxygen which causes a corresponding decrease in the rate. Larger negative currents in relatively reducing environments cause an increase in the rate (Figs. 6-8). Under these conditions any amount of oxide previously existing on the surface must be reduced and this would cause an increase in the rate $(5,6-9,40)$. However, the magnitude of the observed increase can be accounted for only by the additional $\mathrm{CO}$ disproportionation route previously discussed.

Observation (III) emphasizes the important role played by the oxidation state of the catalyst in the oscillatory phenomena observed during $\mathrm{CO}$ oxidation.

Previous solid electrolyte potentiometric studies of the oxidation of ethylene (10-12) and $\mathrm{CO}(40)$ on Pt have shown that at the high-frequency bifurcation between oscillatory and nonoscillatory states the thermodynamic activity $a_{\mathrm{O}}$ of oxygen adsorbed on the catalyst is near to the value which corresponds to the dissociation pressure of 
surface $\mathrm{PtO}_{2}$. This has been taken to indicate that oscillations are caused by formation and destruction of surface $\mathrm{PtO}_{2}$, an idea corroborated by numerous recent independent studies $(6-9,19)$. Within the accuracy of the data the same observation appears to hold also during oxygen pumping. Thus in Fig. 10 the open-circuit emf is $-370 \mathrm{mV}$ and the corresponding (10) surface oxygen activity $\left(a_{\mathrm{O}}=(0.21)^{1 / 2}\right.$ $\left.\exp (2 F E / R T)=1.3 \times 10^{-7} \mathrm{bar}^{1 / 2}\right)$ is well below the dissociation pressure of $\mathrm{PtO}_{2}$ (12) at this temperature $\left(E^{*}=-190 \mathrm{mV}, a_{O}^{*}=\right.$ $\left.2.2 \times 10^{-4} \mathrm{bar}^{1 / 2}\right)$; consequently there are no oscillations. Application of a positive current of $+100 \mu \mathrm{A}$ causes an IR-free catalyst voltage of $-208 \mathrm{mV}\left(a_{0}=9.5 \times 10^{-5}\right.$ bar $^{1 / 2}$ ) which again leads to a nonoscillatory steady state as shown in Fig. 12 (open circles). It is only at higher positive currents causing IR-free catalyst voltages higher than $-190 \mathrm{mV}$ that oscillations appear. From this observation and from the fact that the waveform of the rate and emf oscillations is not altered by oxygen pumping one may conclude that the underlying oscillatory mechanism is the same both under open-circuit conditions and during oxygen pumping.

It is only the limit cycle frequency which changes with current. The observed quasilinear increase in frequency with increasing current is very similar to the frequency increase with increasing $p_{\mathrm{O}_{2}}$ at constant inlet $p_{\mathrm{CO}}$ and temperature observed for low $p_{\mathrm{O}_{2}}$ under open-circuit conditions for the form of relaxation type oscillations described here (40). Thus in both cases an increase in the rate of oxygen supply to the catalyst causes a roughly inversely proportional decrease in limit cycle period. This supports an idea underlying both previous mathematical models developed to describe the oscillatory behavior of ethylene (II) and CO (9) oxidation on $\mathrm{Pt}$, i.e., that the limit cycle period is largely determined by the time required to form a fraction, e.g., onetenth (Ref. (9, Fig. 1)), of a monolayer of $\mathrm{PtO}_{2}$. Indeed at a rate of oxygen supply $G_{\mathrm{O}}$
$=1.04 \times 10^{-9} \mathrm{~g}$ atom $/ \mathrm{s}$ which corresponds to $200 \mu \mathrm{A}$ (Fig. 10) and taking into account that the reactive oxygen uptake of the catalyst (Table 1) is $n_{\mathrm{O}}=3.64 \times 10^{-7} \mathrm{~g}$ atoms $\mathrm{O}$ one computes that the time required to form one-tenth of a monolayer of $\mathrm{PtO}_{2}$ is 70 $\mathrm{s}$, in good agreement with the current induced experimental period of $80 \mathrm{~s}$. The dotted straight lines in Fig. 12 correspond to the expected slope of the frequency dependence on current $\left(\nu=i / 4 \mathrm{Fan}_{\mathrm{O}}\right)$ if the limit cycle period is determined by the time required to form one-tenth $(a=0.1)$ or onefifth $(a-0.2)$ of a monolayer of $\mathrm{PtO}_{2}$. The good agreement between the experimental and the computed frequency dependences on applied current shows that the observed effects of $\mathrm{O}^{2-}$ pumping on the oscillatory behavior of $\mathrm{CO}$ oxidation can be rationalized within the framework of the platinum oxide-based models for $\mathrm{CO}(9)$ and ethylene (11) oxidation on Pt under atmospheric pressure conditions.

\section{CONCLUSIONS}

The intrinsic rate of $\mathrm{CO}$ oxidation on polycrystalline platinum supported on stabilized zirconia can be altered significantly by means of electrochemical $\mathrm{O}^{2-}$ pumping to or from the platinum catalyst. Similarly to previous studies of olefin epoxidation on Ag (23-25), CO hydrogenation on transition metal electrodes $(26,27)$, and to very recent studies of methanol oxidation on $\mathrm{Ag}$ $(43,44)$ and ethylene oxidation on $\mathrm{Pt}(45)$, the observed effect is non-Faradaic; i.e., the observed increase or decrease in reaction rate can exceed the rate of $\mathrm{O}^{2-}$ transport to or from the catalyst by more than two orders of magnitude, leading to enhancement factors as high as 500 . The observed relaxation time constants are of order $2 F n_{\mathrm{O}} / i$, where $n_{\mathrm{O}}$ is the reactive chemisorbed oxygen catalyst uptake. Similar behavior has been observed during light olefin epoxidation $(23-25)$.

The observed effects of positive and small negative $\mathrm{O}^{2-}$ currents on catalyst behavior can be interpreted only in a qualita- 
tive manner by changes in surface coverages of chemisorbed oxygen, $\mathrm{CO}$, and $\mathrm{PtO}_{2}$. It should be emphasized that no quantitative interpretation of the obscrved non-Faradaic phenomena is possible within the framework of classical Langmuir-Hinshelwood or Eley-Rideal kinetic models, unless one postulates the creation of new active catalytic centcrs $(23,24)$ or changes in the binding energies of chemisorbed species resulting from changes in the work function of the metal. Such changes must indeed be taking place during $\mathrm{O}^{2-}$ pumping due to the interaction of oxygen anions with the Pt surface.

The observed dramatic increase in reaction rate with large negative currents and catalyst voltages less than $-1.3 \mathrm{~V}$ strongly indicates that $\mathrm{CO}$ disproportionation and subsequent carbon combustion occur under these conditions and lead to rates of $\mathrm{CO}$ oxidation significantly higher than those obtainable by the usual surface reaction between chemisorbed $\mathrm{O}$ and $\mathrm{CO}$. Oxygen anion pumping to or from the Pt catalyst also has a dramatic effect on the oscillatory behavior of $\mathrm{CO}$ oxidation. The observed phenomena are qualitatively consistent with recent $\mathrm{PtO}_{2}$-based models proposed to describe the oscillatory behavior of CO oxidation on Pt (6-9).

The application of external voltages to solid electrolyte cells with catalytic electrodes appears to be a very powerful means of influencing catalytic phenomena on metals. The use of in situ surface spectroscopic techniques to monitor changes occurring on catalyst surfaces due to $\mathrm{O}^{2-}$ pumping could lead to a better and quantitative understanding of the observed phenomena which are of clear practical as well as theoretical importance.

\section{ACKNOWLEDGMENTS}

We thank the Stiftung Volkswagenwerk of the Federal Republic of Germany for financial support of this work through a Partnership Program Grant awarded to the Institut für Chemische Verfahrenstechnik of the University. of Karlsruhe and to our Institute. We also thank Professors L. Riekert and H.-G. Lintz of the above Institute for numerous helpful discussions and their student Mr. H. Hildebrand for grinding the thin solid electrolyte components. Sincere thanks are also expressed to Dr. J. J. Ehrhard for taking the XPS spectra. We also acknowledge numerous helpful discussions with Professor X. E. Verykios of our Institute.

\section{REFERENCES}

1. Sheintuch, M., and Schmitz, R. A., Catal. Rev. Sci. Eng. 15, 107 (1977).

2. Slin'ko, M. M., and Slin'ko, M. G., Catal. Rev. Sci. Eng. 17, 119 (1978).

3. Engel, T., and Ertl, G., Adv. Catal. 28, 1 (1979).

4. Sheintuch, M., J. Catal. 96, 326 (1985).

5. Razon, L. F., and Schmitz, R. A., Catal. Rev. Sci. Eng. 28, 89 (1986).

6. Turner, J. E., Sales, B. C., and Maple, M. B., Surf. Sci. 103, 54 (1981).

7. Turner, J. E., Sales, B. C., and Maple, M. B., Surf. Sci. 109, 591 (1981).

8. Sales, B. C., Turner, J. E., and Maple, M. B., Surf. Sci. 112, 272 (1981).

9. Sales, B. C., Turner, J. E., and Maple, M. B., Surf. Sci. 114, 381 (1982).

10. Vayenas, C. G., Lee, B., and Michaels, J. N., J. Catal. 66, 36 (1980).

11. Vayenas, C. G., Georgakis, C., Michaels, J. N., and Tormo, J., J. Catal. 67, 348 (1981).

12. Vayenas, C. G., and Michaels, J. N., Surf. Sci. 120, L 405 (1982).

13. Peuckert, M., and Ibach, H., Surf. Sci. 136, 319 (1984).

14. Peuckert, M., and Bonzel, H. P., Surf. Sci. 145, 239 (1984).

15. Berry, R. J., Surf. Sci. 76, 415 (1978).

16. Ertl, G., Norton, R. P., and Rustig, J., Phys, Rev. Lett. 49, 177 (1982).

17. Cox, M. P., Ertl, G., Imbihl, R., and Rustig, J., Surf. Sci. 134, L517 (1983).

18. Imbihl, R., Cox, M. P., Ertl, G., Müller, H., and Brenig, W., J. Chem. Phys. 83, 1578 (1985).

19. Yeates, R. C., Turner, J. E., Gellman, A. J., and Somorjai, G. A., Surf. Sci. 149, 175 (1985).

20. Lindstrom, T. H., and Tsotsis, T. T., Surf. Sci. 167, 1194 (1986).

21. Pancharatnam, S., Huggins, R. A., and Mason, D. M., J. Electrochem. Soc. 122, 869 (1975).

22. Gür, T. M., and Huggins, R. A., J. Electrochem. Soc. 126, 1067 (1979).

23. Stoukides, M., and Vayenas, C. G., J. Catal. 70, 137 (1981).

24. Stoukides, M., and Vayenas, C. G., in "Catalysis under Transient Conditions," p. 181, ACS Symposium Series Vol. 178, 1982.

25. Stoukides, M., and Vayenas, C. G., J. Electrochem. Soc. 131(4), 839 (1984).

26. Gür, T. M., and Huggins, R. A., Science 219, 967 (1983). 
27. Gür, T. M., and Huggins, R. A., J. Catal. 102, 443 (1986).

28. Otsuka, K., Yokoyama, S., and Morikawa, A., Chem. Lett., 319 (1985).

29. Seimanides, S., and Stoukides, M., J. Electrochem. Soc. 133(7), 1535 (1985).

30. Hayakawa, T., Tsunoda, T., Orita, H., Kameyama, T., Takahashi, H., Takehira, K., and Fukuda, K., J. Chem. Soc. Chem. Commun., 961 (1986).

31. Vayenas, C. G., and Farr, R. D., Science 208, 593 (1980).

32. Farr, R. D., and Vayenas, C. G., J. Electrochem. Soc. 127(7), 1478 (1980).

33. Michaels, J. N., and Vayenas, C. G., J. Catal. 85, 477 (1984).

34. Michaels, J. N., and Vayenas, C. G., J. Electrochem. Soc. 131(11) 2544 (1984).

35. Manton, M., Ph.D. thesis, Massachusetts Institute of Technology, 1986.

36. Hetrick, R. E., and Logothetis, E. M., Appl. Phys. Lett. 34, 117 (1979).
37. Okamoto, H., Kawamura, G., and Kudo, T., $J$. Catal. 82, 322 (1985).

38. Erhardt, J. J., Häfele, E., Lintz, H. G., and Martins, A. F., Ber. Bunsenges, Phys. Chem. 89, 894 (1985).

39. Häfele, E., and Lintz, H.-G., Ber. Bunsenges. Phys. Chem. 90, 298 (1986).

40. Yentekakis, I. V., Neophytides, S., and Vayenas, C. G., J. Catal., 111, 152-169.

41. Wang, D. Y., and Nowick, A. S., J. Electrochem. Soc. 128(1), 55 (1981).

42. Sergent, G. D., and Smith, I. W., Fuel 53, 52 (1973).

43. Vayenas, C. G., "Proc. 6th Intern. Conference on Solid State Ionics, Garmisch-Partenkirchen, Sept. 1987;' Solid State Ionics, in press.

44. Neophytides, S., and Vayenas, C. G., in preparation.

45. Bebelis, S., and Vayenas, C. G., in preparation.

46. Yentekakis, I. V., Ph.D. thesis, University of Patras, 1987. 